\title{
A Rare Tropical Stonefly Brahmana flavomarginata (Plecoptera: Perlidae: Acroneuriinae) from Vietnam
}

\author{
Thi Kim Thu $\mathrm{Cao}^{1}$, Yeon Jae Bae ${ }^{2, *}$ \\ ${ }^{1}$ Institute of Ecology and Biological Resources, Vietnam Academy of Science and Technology, \\ Hanoi 10000, Vietnam \\ ${ }^{2}$ Division of Life Sciences, College of Life Sciences and Biotechnology, Korea University, \\ Seoul 136-701, Korea
}

\begin{abstract}
The perlid stonefly Brahmana flavomarginata $\mathrm{Wu}$, originally described from China from the male adult, is described using reared male and female adults and nymphs from Vietnam. The male adult of B. flavomarginata is distinguished from its congeners by the blackish-brown body color and distinct head marking, hemitergal triangular chitin plates, and a median semicircular smooth subgenital plate (hammer) on the abdominal sternum IX. The female adult has a large and round subgenital plate which extends to the posterior margin of the abdominal sternum X. The nymph can be distinguished by the relatively small compound eyes and the body covered by many long stout setae and short golden brown hair-like setae. This species is known in southwestern China (Yunnan Province) and northern Vietnam (Lao Cai Province, Cao Bang Province).
\end{abstract}

Keywords: Brahmana flavomarginata, Acroneuriinae, Perlidae, description, Vietnam

\section{INTRODUCTION}

The tropical or subtropical stonefly genus Brahmana, a member of the subfamily Acroneuriinae in the family Perlidae, was established by Klapálek (1914). The adult of the genus is characterized by the deeply inserted head to the pronotum, by the absence of crossveins between $2 \mathrm{~A}$ and $3 \mathrm{~A}$ in males, and by the large subgenital plate which covers almost entire area of the abdominal sternum IX in females (Wu, 19371938).

Members of Brahmana are known from insular and peninsula Southeast Asia to Indian subcontinent, including China, Nepal, and the Himalayas (Klapálek, 1916), and 5 species are known from the region (Klapálek, 1916; Du et al., 1999): $B$. benigna (Needham, 1909), B. chrysostoma Klapálek (1916), B. microphthalma Klapálek (1916), B. suffusa (Walker, 1852), and B. flavomarginata $\mathrm{Wu}$ (1962). Except for B. flavomarginata Wu (1962), the remaining 4 species were described based only on the female adult, and the locations of the type specimens are not specified. According to previous studies including our recent investigations, more than 113 Perlidae species belonging to 7 genera are known in Tropical South- east Asia (Cao and Bae, 2007, 2010; Cao et al., 2007).

We have investigated $B$. flavomarginata $\mathrm{Wu}$ from mountain streams in northern Vietnam and successfully reared the male and female adults from the nymphs. We herein provide descriptions, illustrations, and material information for all the stages of the species.

Adult specimens were collected by a sweep net and a light trap. Nymphs were collected by a hand net. Last instar nymphs were reared in the field to associate the adults. All materials were preserved in $80 \% \mathrm{EtOH}$, and housed in the Entomological Museum of Korea University (KU) in Seoul, Korea and the Institute of Ecology and Biological Resources (IEBR) in Hanoi, Vietnam. Morphological terminology follows Stark and Gaufin (1976).

\section{SYSTEMATIC ACCOUNTS}

Order Plecoptera Burmester

Family Perlidae Latreille

Genus Brahmana Klapálek

Brahmana Klapálek, 1914: 67.
(C) This is an Open Access article distributed under the terms of the Creative Commons Attribution Non-Commercial License (http://creativecommons.org/ licenses/by-nc/3.0/) which permits unrestricted non-commercial use, distribution, and reproduction in any medium, provided the original work is properly cited.

pISSN 2234-6953 eISSN 2234-8190
*To whom correspondence should be addressed

Tel: 82-2-3290-3408, Fax: 82-2-3290-3963

E-mail: yjbae@korea.ac.kr 
Type species. Brahmana suffusa Walker, designated by Klapálek (1916).

\section{Brahmana flavomarginata Wu (Figs. 1-3)}

Brahmana flavomarginata Wu, 1962: 150 (type: male adult).

Material examined. 7 male adults (SWU-PLE-53, 54, reared), 2 female adults (SWU-PLE-52, reared), 2 nymphs (SWUPLE-51), Thac Bac $\left(22^{\circ} 21^{\prime} 887^{\prime \prime} \mathrm{N}, 103^{\circ} 46^{\prime} 666^{\prime \prime} \mathrm{E}\right)$, alt. 2,000 m, Sa Pa, Lao Cai Province, Northern Vietnam, 22 Apr 2002, Hoang Duc Huy and Nguyen Van Vinh [KU]; 2 nymphs (IEBR-PLE-50), Nam Toong (22 $\left.32^{\prime} 643^{\prime \prime} \mathrm{N}, 105^{\circ} 51^{\prime} 494^{\prime \prime} \mathrm{E}\right)$,
Nguyen Binh, Cao Bang Province, Northern Vietnam, 11 May 2010, Thi Kim Thu Cao [IEBR].

Male adult. Body length $15.6-17.5 \mathrm{~mm}$; antennae 10.1-13.4 $\mathrm{mm}$; forewings $16.5-18.3 \mathrm{~mm}$; hindwings $15.3-16.6 \mathrm{~mm}$. General body color blackish-brown. Head (Fig. 1A) slightly narrower than pronotum, with a triangular darkened area centrally. Three small ocelli present; anterior ocellus somewhat indistinct. Antennae generally blackish-brown. Pronotum (Fig. 1A) blackish-brown, oval; lateral margins lighter in color. Wings (Fig. 1B, C) subhyaline, somewhat smoky at tip and along veins; veins brown. Forewing Rs with 4 branches; C-Sc with 19 crossveins. Hindwing 3A unforked. Legs
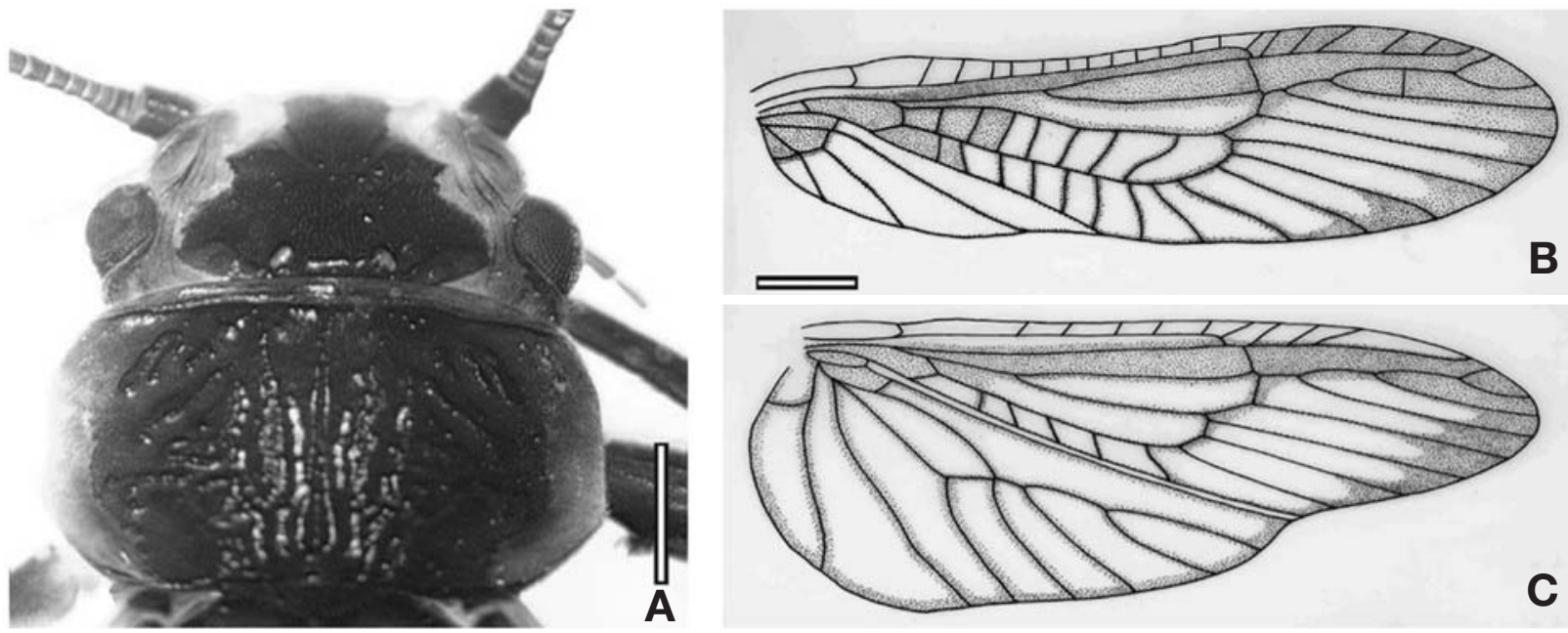



B
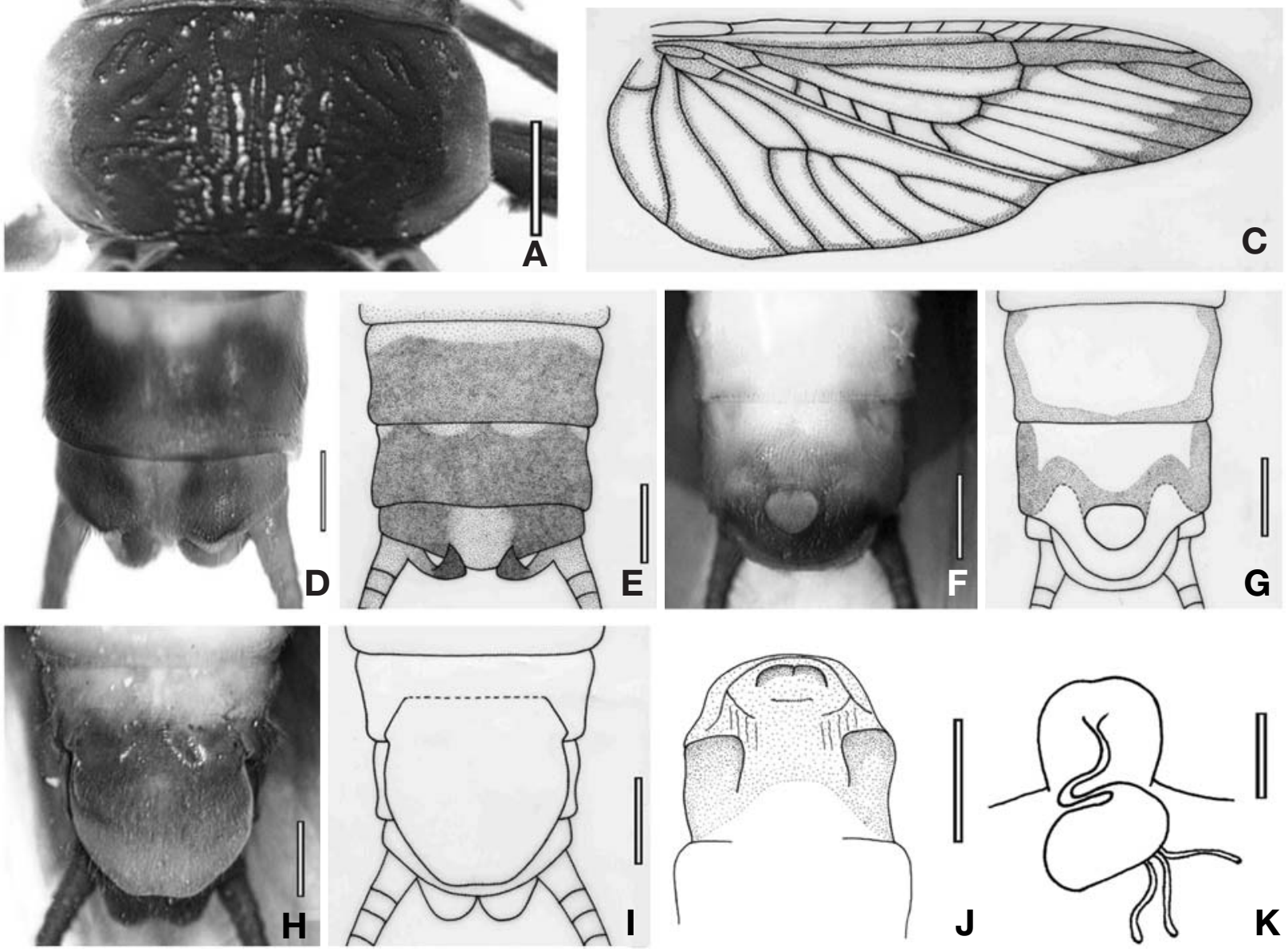

Fig. 1. Brahmana flavomarginata Wu, adult. A, Male head and pronotum; B, C, Male forewing and hindwing; D, E, Male dorsal terminalia; F, G, Male ventral terminalia; H, I, Female ventral terminalia; J, Everted aedeagus, dorsal view; K, Female vagina. Scale bars: $A=1 \mathrm{~mm}, \mathrm{~B}, \mathrm{C}=2 \mathrm{~mm}, \mathrm{D}-\mathrm{K}=0.5 \mathrm{~mm}$. 


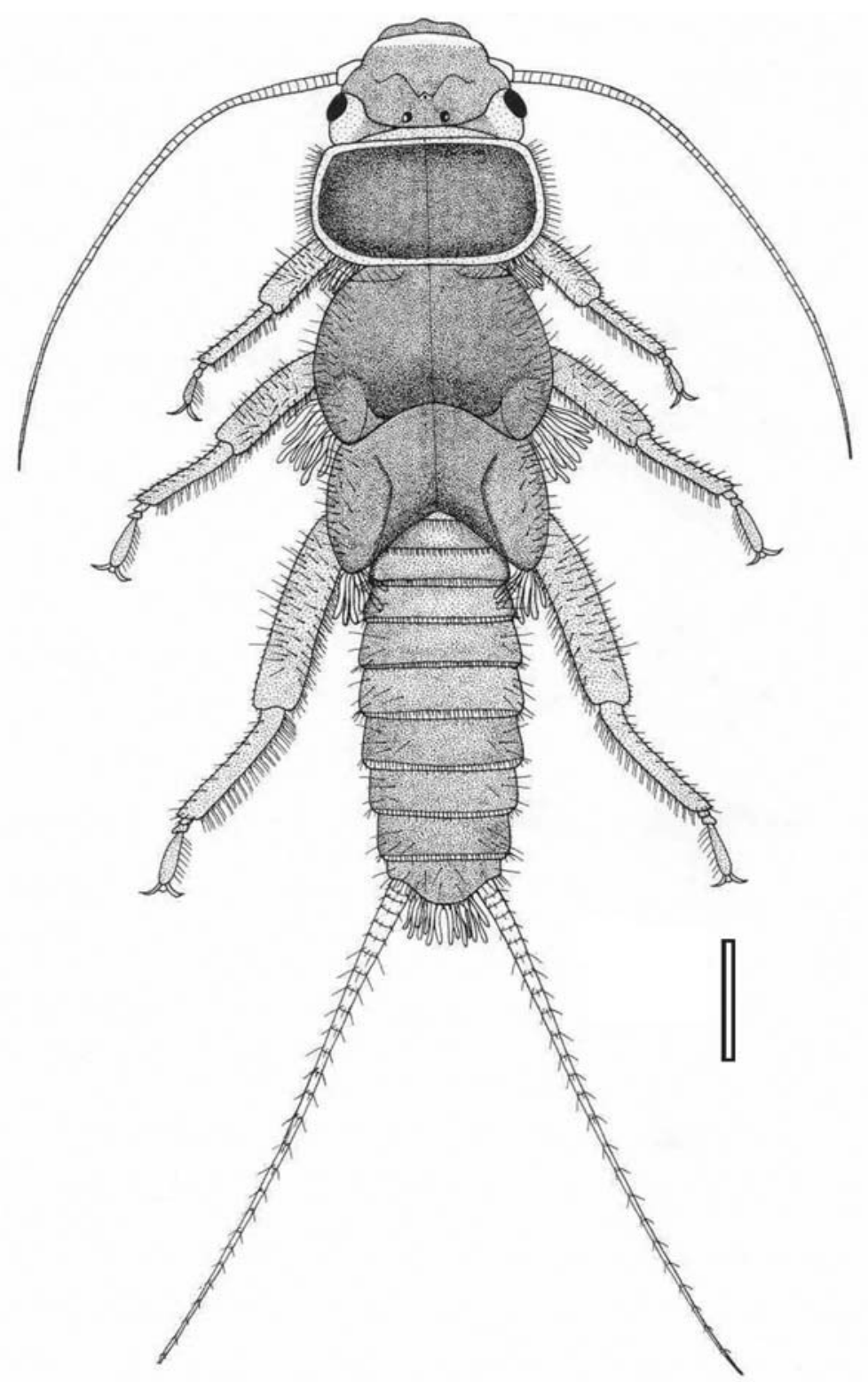

Fig. 2. Brahmana flavomarginata Wu, nymphal habitus. Scale bar $=2 \mathrm{~mm}$.

unicolored in blackish-brown. Abdomen cylindrical, blackish-brown; abdominal terga I-X unmodified. Paraprocts (Fig. 1D, E) modified to hemitergal; hemitergal triangular chitin plates recurved backward and upward, slightly extended over posterior margin of abdominal tergum X. Subgenital plate (Fig. 1F, G) on abdominal sternum IX broadly rounded at posterior margin, covered almost entire area of abdominal sternum X, with a semicircular smooth hammer medially. Everted aedeagus sac (Fig. 1J) bare, relatively short and plump, ca. $0.7 \mathrm{~mm}$ long, lepidopteran pupa head-shaped in dorsal view; apical part armed with small sclerotized bilobed structure medially; basal part with a pair of longitudinal pro- trusions. Cerci blackish-brown; each joint with whorl of long setae on posterior margin.

Female adult. Body length 18.1-18.5 mm; forewings $18.5-$ $19.0 \mathrm{~mm}$; hindwings $16.3-17.5 \mathrm{~mm}$. Similar morphology to male but somewhat larger. Subgenital plate (Fig. 1H, I) relatively large, round, slightly narrowed posteriorly, and extending to posterior margin of abdominal sternum X. Vagina (Fig. 1K) small, membranous, and without anterior accessory glands. Spermatheca usually inflated and with several accessory glands; spermathecal stalk slender, slightly longer than vagina length.

Nymph. Body length 14.7-17.9 mm. General body (Fig. 2) 

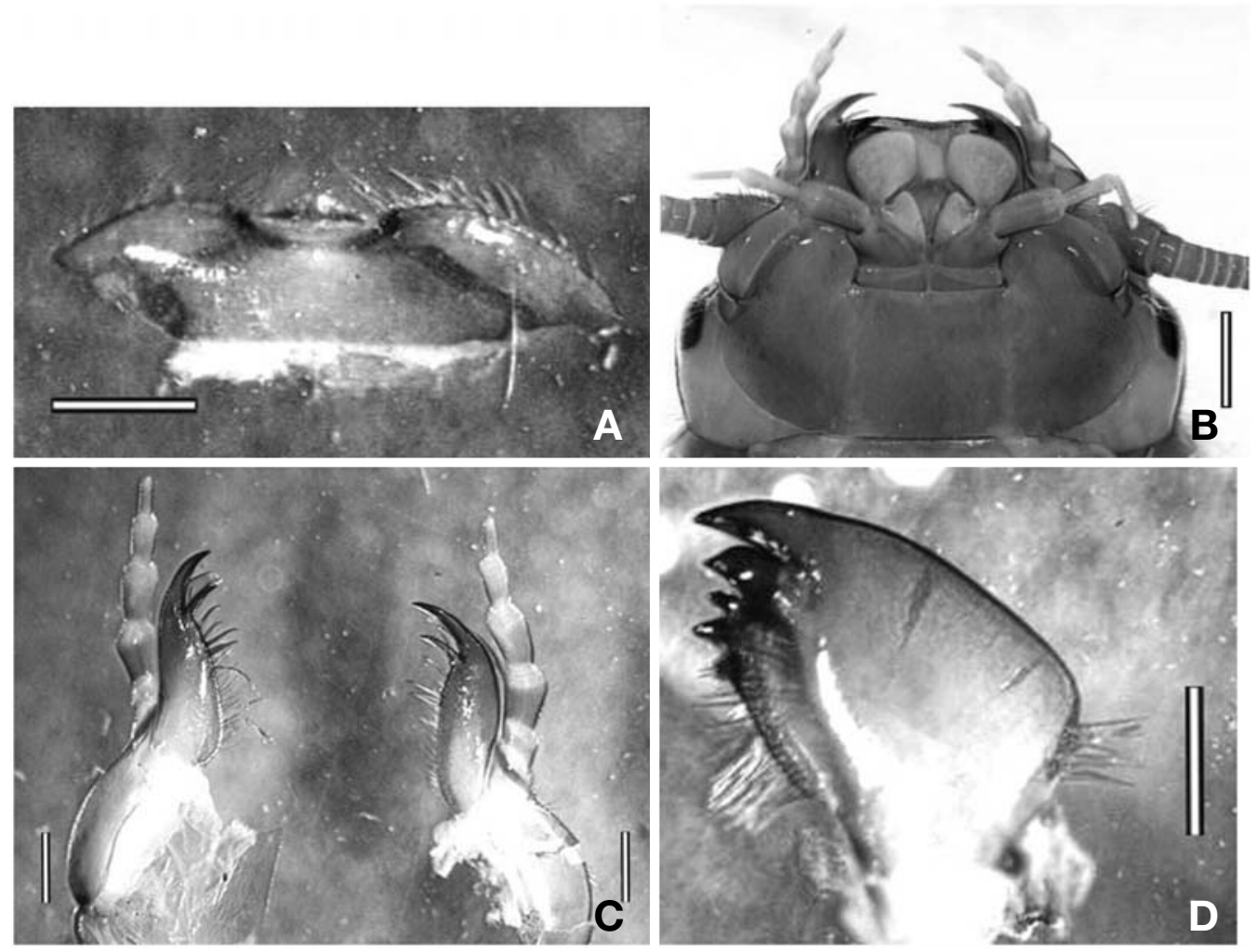

Fig. 3. Brahmana flavomarginata Wu, nymphal mouthparts. A, Labrum; B, Labium; C, Left and right maxilla; D, Right mandible. Scale bars: $A-C=0.5 \mathrm{~mm}, D=1 \mathrm{~mm}$.

color yellowish-brown without distinct pattern; surface covered with many long stout setae and short golden brown hairlike setae. Head relatively wide, as wide as pronotum (head width $3.6-5.8 \mathrm{~mm}$ ), flattened, with pale-brown to indistinct M-line; occipital ridge slightly convex at middle, without fringe of stout setae. Compound eyes relatively small and black. Three ocelli present; anterior ocellus very small, similar to black spot. Antennae long, ca. $1 / 2 \times$ as long as body length (antennae length 6.7-8.6 mm), yellowish-brown, with several minute hairs on scape. Mouthparts brown. Labrum (Fig. 3A) dorsally covered with black hair-like setae, ca. 4.0 $\times$ wider than long; anterior margins convex at middle, fringed with white silky hair-like setae. Labium (Fig. 3B) with well developed and round paraglossae; glossae greatly reduced; submentum very large, wider than long, with round margin; mentum reduced to narrow band; labial palp slender, 3segmented (segments nearly equal in length). Hypopharynx triangular; anterior margin round and cover with patch of strong brown hair-like setae. Mandibles (Fig. 3D) asymmetrical; right mandible with six teeth and left mandible with five teeth; with two rows of setae on inner margin and ca. 10 setae on outer margin near base. Maxillae (Fig. 3C) well developed; lacinia bidentate; inner tooth ca. $2 / 3 \times$ as long as outer tooth; inner lacinial margin with ca. 5 large setae followed by a row of smaller setae; maxillary palps short and stout, 5-segmented (segments subequal in length). Pronotum quadrate, yellowish-brown, wider than long, with complete fringe of thick setae along lateral margin. Legs flattened, yellowishbrown; femora and tibiae covered with numerous stout setae. Abdomen cylindrical, yellowish-brown, covered with many long stout setae and short golden brown hair-like setae, with anal gills. Paraproct lobe quadrate. Cerci relatively long, as long as body length, yellowish-brown; each joint with whirl of stout setae on posterior margin.

Diagnosis. The male adult of Brahmana flavomarginata can be distinguished from its congeners by the blackish-brown body color and distinct dark marking on head (Fig. 1A). In addition, the feature of the everted aedeagus is unique among congener species (Fig. 1J). The female adult of B. flavomarginata can be distinguished by the round subgenital plate on the abdominal sternum VIII, which extends to the posterior margin of the abdominal sternum IX (Fig. 1I). The nymphs can be distinguished by the relatively small compound eyes and body surface covered with many long stout setae and short golden brown hair-like setae (Fig. 2).

Distribution. Southwestern China (Yunnan Province), Nor- 
thern Vietnam (Lao Cai Province, Cao Bang Province).

Remarks. In the genera of the tribe Acroneuriini, Brahmana Klapálek appears to be closely related to the genus Hemacroneuria Enderlein by their shared characters of the inserted head to the pronotum in male adults and by the large subgenital plate which covers almost entire area of the abdominal sternum IX in female adults (Stark and Sivec, 2008). Based on our close examination on the Vietnamese material, these two genera differ in the absence of rowed knobs of triangular spines on the abdominal tergum $\mathrm{X}$ in Brahmana, as is also the case in B. flavomarginata. Stark and Sivec (2008) provided diagnostic characters to distinguish males of several related genera of Acroneuriinae.

Wu (1962) originally described B. flavomarginata based only on male adult specimens from Yunnan Province in southwestern mainland China. We successfully reared both of the male and female adults of $B$. flavomarginata from the last instar nymphs. No eggs were contained in the examined female adults.

\section{ACKNOWLEDGMENTS}

The adult materials used herein were kindly made available by Dr. Nguyen Van Vinh (Ha Noi University of Science, Hanoi) and Dr. Hoang Duc Huy (Ho Chi Minh University of Science, Ho Chi Minh). This work was supported by a research grant from National Foundation for Science and Technology Development (NAFOSTED-106.12.29.09) in Vietnam.

\section{REFERENCES}

Cao TKT, Bae YJ, 2007. New species of Acroneuria (Plecoptera: Perlidae: Acroneuriinae) from tropical Southeast Asia. Journal of the Kansas Entomological Society, 80:192-204.

Cao TKT, Bae YJ, 2010. Togoperla thinhi, a new stonefly from central Vietnam (Plecoptera: Perlidae). Animal Cells and Systems, 14:221-224.

Cao TKT, Ham SA, Bae YJ, 2007. Description of three new species of Neoperla (Plecoptera: Perlidae) and a historical review of tropical Southeast Asian Perlidae. Zootaxa, 1453: 41-54.

Du Y, Sivec I, He J, 1999. A checklist of the Chinese species of the family Perlidae (Plecoptera: Perloidea). Acta Entomologica Slovenica, 7:59-67.

Klapálek F, 1914. Analytická tabulka fam. Perlidae a její dvou subfam., Perlinae a Acroneuriinae (Plecoptera). České Společnosti Entomologické, 11:53-69.

Klapálek F, 1916. Subfamilia Acroneuriinae Klapálek. Casopis České Společnosti Entomologické, 13:45-84.

Stark BP, Gaufin AR, 1976. The Nearctic species of Acroneuria (Plecoptera: Perlidae). Journal of the Kansas Entomological Society, 49:221-253.

Stark BP, Sivec I, 2008. Systematic notes on Kiotina Klapálek and Hemacroneuria Enderlein (Plecoptera: Perlidae), with description of four new species. Illiesia, 4:161-175.

Wu CF, 1937-1938. The stoneflies of China (Order Plecoptera). Peking Natural History Bulletin, 12:225-252.

Wu CF, 1962. Results of the zoologico-botanical expedition to Southwest China, 1955-1957 (Plecoptera). Acta Entomologica Sinica, 11:139-153 (in Chinese with English summary).

Received September 2, 2012

Revised January 12, 2013

Accepted January 15, 2013 